\title{
CORRELATION BETWEEN CORPUS LUTEUM VOLUME USING 2D ULTRASOUND AND COLOR- DOPPLER STUDY OF CORPUS LUTEUM VASCULATURE WITH MATERNAL SERUM CA-125 LEVEL IN PROGNOSIS OF FIRST TRIMESTER THREATENED ABORTION
}

By

\section{Ayman Aly Abd El-Rahman Nafea, Yahia Abd El-Salam Wafa, Osama El-Saeed Ali and Wael Refaat Hablas*}

Departments of Obstetrics and Gynecology and Clinical Pathology*, Faculty of Medicine, Al-Azhar University

Corresponding author: Ayman Aly Abd El-Rahman Nafea,

E-mail: dr.ayman.nafea@gmail.com

\begin{abstract}
Background: Threatened miscarriage is a common complication in the first trimester of pregnancy and is often associated with anxiety regarding pregnancy outcome. Approximately, $20 \%$ of pregnant women have symptoms of threatened abortion in the first trimester of pregnancy. A single serum cancer antigen 125 (CA125) level determination is valuable in women with imminent abortion presenting with abdominal pain, vaginal bleeding or both rather than serial measurements.

Objective: To evaluate the prognostic value of correlating the corpus luteum volume measured by twodimensional ultrasound, and color doppler blood flow changes in the corpus luteum together with the results of serum CA-125 at the time of initial presentation with pregnancy outcome in patients with first trimesteric threatened abortion.

Patients and methods: This prospective controlled study was held during the period from May 2015 to May 2018 on 100 women on their first trimester of pregnancy, 50 women having normal uncomplicated pregnancy and 50 women with clinical diagnosis of threatened abortion. The latter group was further subdivided into: group of patients who aborted (14 patients), and another group who continued their pregnancy and proceeded into the second trimester (36 patients).
\end{abstract}

Results: It was found that the mean corpus luteum peak systolic velocity (CL PSV) for the threatened abortion (aborted) group was $30.68 \pm 18.9 \mathrm{~cm} / \mathrm{sec}$, while for the threatened abortion (continued) group was $22.03 \pm 12.9 \mathrm{~cm} / \mathrm{sec}$, and for the control group was $21.58 \pm 13.77 \mathrm{~cm} / \mathrm{sec}$. The difference was statistically significant between threatened abortion (aborted) group and each of the threatened abortion (continued) group and the control group. The difference was statistically non-significant between the threatened abortion (continued) group, and the control group. The cut-off value of CL PSV at which there was a high probability of termination of pregnancy in threatened abortion cases, reached $17.785 \mathrm{~cm} / \mathrm{sec}$ with a sensitivity of $63.6 \%$ and specificity of $54.4 \%$.

Conclusion: Serum CA-125 level determination was valuable in the women with symptoms of threatened abortion with a cut-off limit of $31.85 \mathrm{IU} / \mathrm{ml}$ of CA-125 level which carried a sensitivity of $86.4 \%$ and specificity of $80.7 \%$. The study suggested that CA- 125 may be a cheap, sensitive and specific method in prediction of the cases of threatened abortion.

Keywords: Abortion, Corpus Luteum Volume, 2D Ultrasound and Color-Doppler, Serum CA-125. 


\section{INTRODUCTION}

Spontaneous abortion or miscarriage is defined as a clinically recognized pregnancy loss before the 20th week of gestation, or defined as expulsion or extraction of an embryo or fetus weighing $500 \mathrm{~g}$ or less (Silver, 2011).

Ultrasound studies have shown a potential to provide information about the fetus in a noninvasive manner. Most importantly, it does not appear to be associated with any known adverse fetal bioeffects. Thus, diagnostic ultrasound gained wide clinical acceptance and became of considerable diagnostic value. The new powerful ultrasound machines, with superb resolution and various doppler modalities are convenient to use, comfortable for the patient, and not very expensive (Predanic et al., 2010).

The first trimester basic ultrasound is typically performed to confirm a viable intrauterine pregnancy. The exam may be performed either trans-abdominally or trans-vaginally. It is ideally performed before 13 weeks and 6 days of gestation. Ultrasound examination at this time aids in the clinical assessment of pelvic pain and/or vaginal bleeding in the setting of an early pregnancy because it can diagnose an extra uterine pregnancy or an abnormal pregnancy, such as a hydatidiform molar pregnancy, an anembryonic gestation or an incomplete versus complete abortion (Kim et al., 2017).

The corpus luteum, a well-identified structure in one of the ovaries in early pregnancy, has a wide range of sonographic morphologies. In 2D static imaging, multiple lines of information are reconstructed to form a 2 dimensional image. The unit of stored information at the $2 \mathrm{D}$ level is the pixel. The file of volume information can be retrieved from the machine's memory. 2D ultrasound allows observing two of three orthogonal planes. Examiners, can of course, observe different planes by changing the transducer position but, at any given time, only two planes can be seen on the screen, never the third (Devoto et al., 2011).

CA125 turned out to be a valuable parameter not only as a marker of ovarian carcinoma but also in other fields of obstetrics and gynecology. Acute elevations of maternal serum CA-125 levels in threatened pregnancies terminating eventually in spontaneous abortion. The low level of cord blood CA125 in cases of fetal demise indicates that the elevation in maternal serum CA-125 level is not of fetal origin and should therefore reflect the degree of decidual destruction in cases of threatened abortion (Mahdi, 2010).

In pregnancy, CA-125 increases in the first trimester. Regarding the level of CA125 in pregnancy, conflicting results have been reported. The highest level of CA125 could be detected in the sera of women with threatened abortion (Cunningham et al., 2010).

The present study aimed to evaluate the prognostic value of correlating the corpus luteum volume measured by twodimensional ultrasound, and color Doppler blood flow changes in the corpus luteum together with the results of serum CA-125 at the time of initial presentation with pregnancy outcome in patients with first trimesteric threatened abortion. 


\section{PATIENTS AND METHODS}

This prospective controlled study was held during the period from May 2015 to May 2018 on 100 patients attended the outpatient clinic or the causality department of Obstetrics \& Gynecology, Al-Ahrar Teaching Hospital in Zagazig. This study included 2 equal groups:

Study group with clinical diagnosis of threatened abortion in their 1st trimester of pregnancy, attended the outpatient clinic or the causality department giving a history of bloody vaginal discharge or vaginal bleeding. The study group was further subdivided into group of patients who aborted (14 patients) and another group who continued their pregnancy and proceeded into the second trimester (36 patients).

Control group in their 1st trimester of pregnancy, having normal uncomplicated pregnancy, attending the outpatient clinic for routine antenatal care.

\section{Inclusion criteria:}

- Patients in their 1st trimester of a singleton pregnancy presenting with vaginal bleeding or spotting.

- A visible gestational sac of a living embryo verified by cardiac activity visualized on real time ultrasound.

- Maternal age ranges between (20-35) years.

- Gestational age (8-12 weeks) calculated from the 1st day of the last normal menstrual period, preceded by 3 regular menstrual cycles, and correlating with ultrasound measurements, together with positive urinary pregnancy test.
- Spontaneous pregnancy, i.e no history of induction of ovulation or ART.

\section{Exclusion criteria:}

- History of general medical diseases e.g. diabetes.

- Presence of local (gynecological) diseases e.g. fibroid or adenexal masses verified by normal appearance of the uterus and ovaries by ultrasound.

- Presence of uterine malformations, e.g hypoplastic uterus or septate uterus.

- Patients with history of recurrent abortion.

- History of any maternal disease that would cause an increase in CA-125 level. These diseases include gynecological conditions such as chronic pelvic infection and endometriosis; and non-gynecological conditions such as: hepatic, renal, and lung diseases.

All patients were subjected to the following:

- Verbal consent.

- Detailed clinical history:

- Personal history: Name, age, parity, occupation, residency and special habits.

- Present history: History of onset, course and duration of vaginal bleeding or bloody vaginal discharge.

- Obstetric history: History of previous preterm labor, previous abortion, previous full-term deliveries, mode of delivery and fetal outcome. 
- Menstrual history: For estimation of gestational age using Naegele's rule, if she had regular cycles for the last three months before she got pregnant and was not taking contraceptive pills during this period and she was sure of her dates.

- Past history: History of medical disorders, abdominal surgeries, drug therapy or allergy or history of intake of other tocolytic drugs.

- Family history: For any similar condition.

- General and local clinical examination with special attention to pelvic examination to assess the state of the cervix in order to confirm the diagnosis of threatened abortion and to assess vaginal bleeding.

- Transvaginal ultrasonographic examination including color-Doppler using "GE VOLUSON 730 PRO V" to assess the following data:

- Gestational age.

- Fetal viability.

- Measurement of the cervix to ascertain that the cervix is closed.

- Exclusion of any uterine or ovarian lesions.

- Exclusion of uterine malformations.

- Measurement of corpus luteum volume using two-dimensional (2D) ultrasound.

- Measurement of the pulsitility index and peak systolic velocity of the corpus luteum vessels.

- Venous blood sample was obtained from each patient on the same day of ultrasound examination for evaluation of maternal serum CA-125.

Follow up of patients was carried out until 20 weeks of pregnancy.

Corpus luteum volume, and color doppler blood flow changes in the corpus luteum together with the results of serum CA-125 were correlated to the outcome of pregnancy of the patients.

\section{Comparison was done between the two} study subgroups: threatened abortion (aborted) group and threatened abortion (continued) group, and the control group, and between each of the study subgroups with one another and also each with the control group in order to determine the utility of color-doppler sonography of corpus luteum vessels, presence or absence of corpus luteum, volume of corpus luteum, in addition to level of serum CA-125 in predicting the outcome of first-trimester gestations.

\section{Statistical analysis:}

Data were statistically described in terms of range, mean \pm standard deviation, frequencies (number of cases) and percentages when appropriate. Comparison of numerical variables between the study groups was done using one-way analysis of variance (ANOVA) test with posthoc multiple 2-group comparisons. For comparing categorical data. Exact test was used. Accuracy was represented using the terms sensitivity, and specificity. Receiver operator characteristic (ROC) analysis was used to determine the optimum cut off value for the studied diagnostic markers. P-value less than 0.05 were considered statistically significant. All statistical calculations were done using computer programs 
Microsoft Excel 2016 (Microsoft Corporation, NY, USA) and SPSS Sciences; SPSS Inc., Chicago, IL, USA) (Statistical Package for the Social version 15 for Microsoft Windows.

\section{RESULTS}

When comparing the three study groups, it was found that the mean maternal age for the threatened abortion (aborted) group was 23.5 \pm 2.77 years, for the threatened abortion (continued) group

was $24.18 \pm 3.15$ years, and for the control group was $23.55 \pm 2.68$ years. The p-value was 0.564 , statistically non-significant (Table 1).

Table (1): Comparison of the three study groups according to the maternal age

\begin{tabular}{|c|c|c|c|}
\hline Garameters & $\begin{array}{c}\text { Threatened abortion } \\
\text { (aborted group) }\end{array}$ & $\begin{array}{c}\text { Threatened abortion } \\
\text { (continued group) }\end{array}$ & $\begin{array}{c}\text { Control } \\
\text { group }\end{array}$ \\
\hline Number of patients & 14 & 36 & 50 \\
\hline Age range (years) & $20-29$ & $20-35$ & $20-34$ \\
\hline Mean age \pm SD & $23.5 \pm 2.77$ & $24.18 \pm 3.15$ & $23.55 \pm 2.68$ \\
\hline P value & \multicolumn{3}{|l}{0.564} \\
\hline
\end{tabular}

When comparing the three study groups, it was found that the mean corpus luteum volume for the threatened abortion (aborted) group was $3.34 \pm 1.2 \mathrm{~cm} 3$, for the threatened abortion (continued) group was $4.74 \pm 0.8 \mathrm{~cm} 3$ while for the control group was $4.43 \pm 0.8 \mathrm{~cm} 3$. The $\mathrm{p}$-value was < 0.05 (Table 2).

Table (2): Comparison of the three study groups according to corpus luteum volume

\begin{tabular}{|c|c|c|c|}
\hline \multirow{2}{*}{ Group } & \multicolumn{2}{|c|}{ Threatened group } & \multirow{2}{*}{ Control group } \\
\cline { 2 - 3 } Parameters & Aborted group & Continued group & 50 \\
\hline Number of patients & 14 & 36 & $2.99-5.93$ \\
\hline Range (cm $\left.\mathbf{c m}^{\mathbf{3}}\right)$ & $1.4-5.9$ & $3.1-6.01$ & $(4.43 \pm 0.8) \mathrm{a}$ \\
\hline Mean \pm SD & $(3.34 \pm 1.2) \mathrm{b}$ & $(4.74 \pm 0.8) \mathrm{a}$ & \\
\hline P value & \multicolumn{3}{|c}{$0.00^{*}$} \\
\hline
\end{tabular}

$P$ of $(\mathrm{F})$ test (ANOV) Analysis Of Variance.

LSD - The alphabet (a-b) of different alphabet are significate.

When comparing the three study groups, corpus luteum was absent in 3 out of 14 cases $(21.4 \%)$ of threatened abortion who aborted afterwards and was present in the remaining 11 cases $(78.6 \%)$, while corpus luteum was present in all the cases $(100 \%)$ of both threatened abortion cases who continued their pregnancy into the second trimester (36 cases) and the controls (50 cases). The overall percentage of absent corpus luteum among the three study groups was 3\%, and the percentage of the present corpus luteum was $97 \%$. The $\mathrm{p}$-value was $<0.05$ (Table 3).

Table(3): Comparison of the three study groups according to presence or absence of corpus luteum 
Ayman A. A. Nafea et al.,

\begin{tabular}{|c|c|c|c|c|c|}
\hline \multirow{2}{*}{ Corpus luteum } & \multicolumn{2}{|c|}{ Threatened abortion } & \multirow{2}{*}{ Control } & \multirow{2}{*}{ Total } \\
\cline { 3 - 5 } & Count & Aborted & Continued & & \\
\hline \multirow{2}{*}{ No } & \% within group & $21.4 \%$ & $0 \%$ & $0 \%$ & $3 \%$ \\
\hline \multirow{2}{*}{ Yes } & Count & 11 & 36 & 50 & 97 \\
\cline { 2 - 6 } & \% within group & $78.6 \%$ & $100 \%$ & $100 \%$ & $97 \%$ \\
\hline \multicolumn{2}{|c|}{ P value } & \multicolumn{3}{|c|}{$<0.001$} \\
\hline
\end{tabular}

$\mathrm{P}$ of Fisher exact $\mathrm{t}$ test.

When comparing the three study groups, it was found that the level of serum CA125 for the threatened abortion (aborted) group was $51.1 \pm 14.6 \mathrm{IU} / \mathrm{ml}$, for the threatened abortion (continued) group was $22.7 \pm 10.8$ while for the control group was $16.8 \pm 8.4 \mathrm{IU} / \mathrm{ml}$. The p-value was < 0.05 (Table 4).

Table(4): Comparison of the three study groups according to the maternal serum CA125 level

\begin{tabular}{|c|c|c|c|}
\hline \multirow{2}{*}{$\begin{array}{l}\text { Parameters } \\
\text { for CA125 }\end{array}$} & \multirow{2}{*}{ Control } & \multicolumn{2}{|c|}{ Threatened abortion } \\
\cline { 3 - 4 } & & Aborted & Continued \\
\hline Number of patients & 50 & 14 & 36 \\
\hline Median & $(11.4) \mathrm{a}$ & $(45.7) \mathrm{b}$ & $(31.5) \mathrm{c}$ \\
\hline Mean \pm SD & $16.8 \pm 8.4$ & $51.1 \pm 14.6$ & $22.7 \pm 10.8$ \\
\hline Range & $4.8-32.1$ & $29.3-79.1$ & $5.8-38.3$ \\
\hline P value & \multicolumn{3}{|c}{$0.00^{*}$} \\
\hline
\end{tabular}

P of Kruskall Wallis U test

The alphabet $(a-b)$ of different alphabet is significate

On doing a ROC Curve for CA-125 in predicting termination of pregnancy in threatened abortion cases, the cut-off limit of $31.9 \mathrm{IU} / \mathrm{ml}$ of CA-125 level achieved sensitivity of $85.7 \%$ and specificity of $80.6 \%$ (Figure 1). 


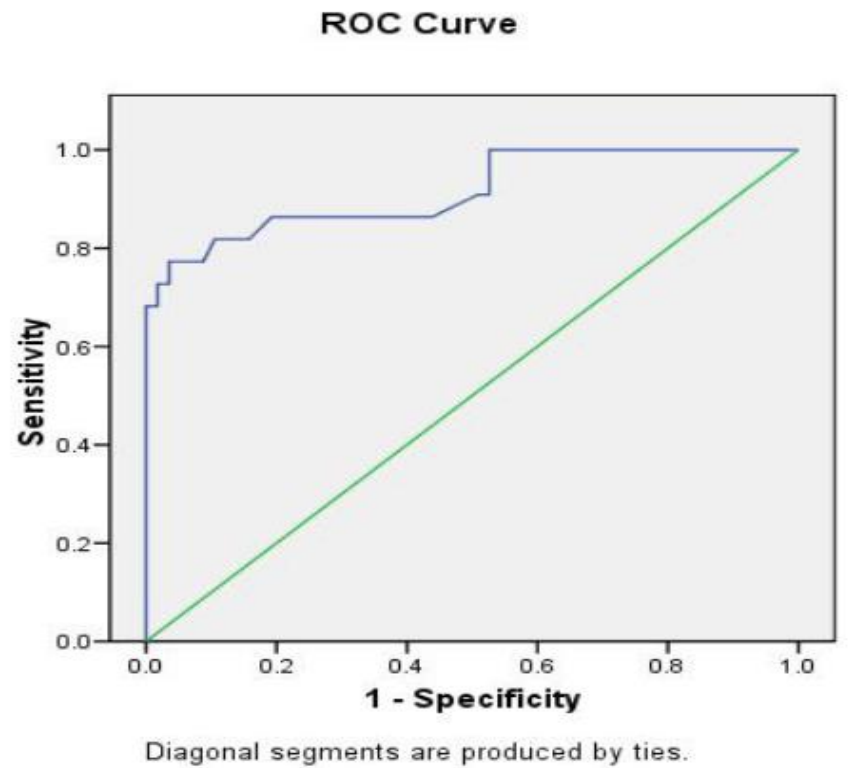

Figure (1): ROC Curve for $\mathrm{CA}-125$ in predicting termination of pregnancy in threatened abortion cases

On doing a ROC curve for CL PSV in predicting termination of pregnancy in threatened abortion cases, the cut-off limit of $17.8 \mathrm{~cm} / \mathrm{sec}$ achieved sensitivity of $64.5 \%$ and specificity of $55.6 \%$ (Figure 2).

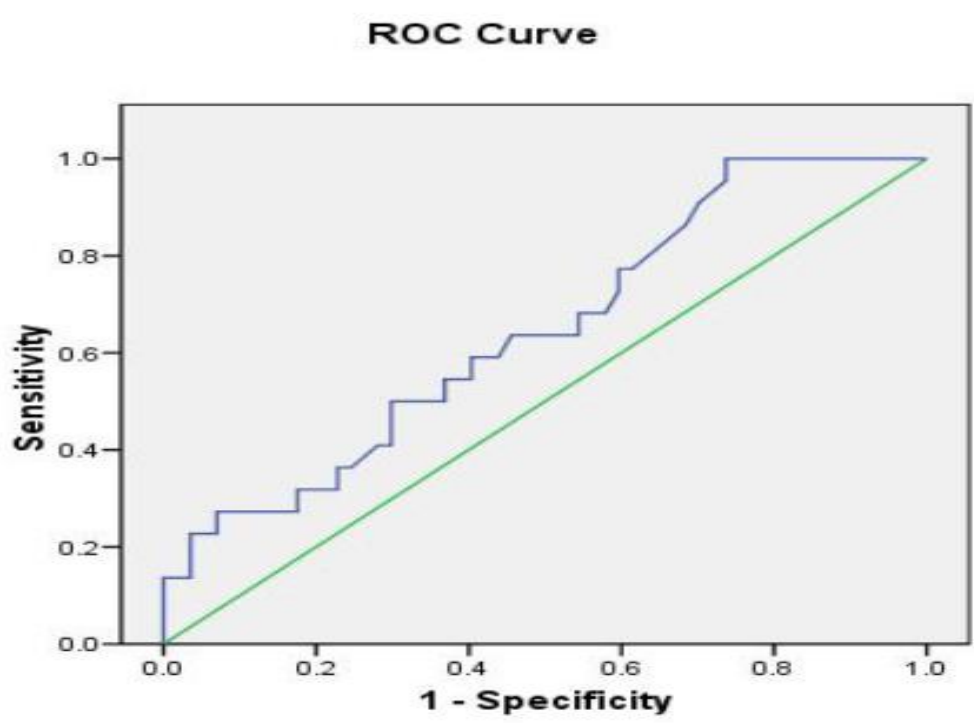

Diagonal segments are produced by ties.

Figure (2): ROC Curve for corpus luteum PSV in predicting termination of pregnancy in threatened abortion cases 
On doing a ROC curve for CL volume in predicting termination of pregnancy in threatened abortion cases, the cut-off limit of $4.1 \mathrm{~cm} 3$ achieved sensitivity of $85.7 \%$ and specificity of $83.3 \%$ (Figure 3).

\section{ROC Curve}

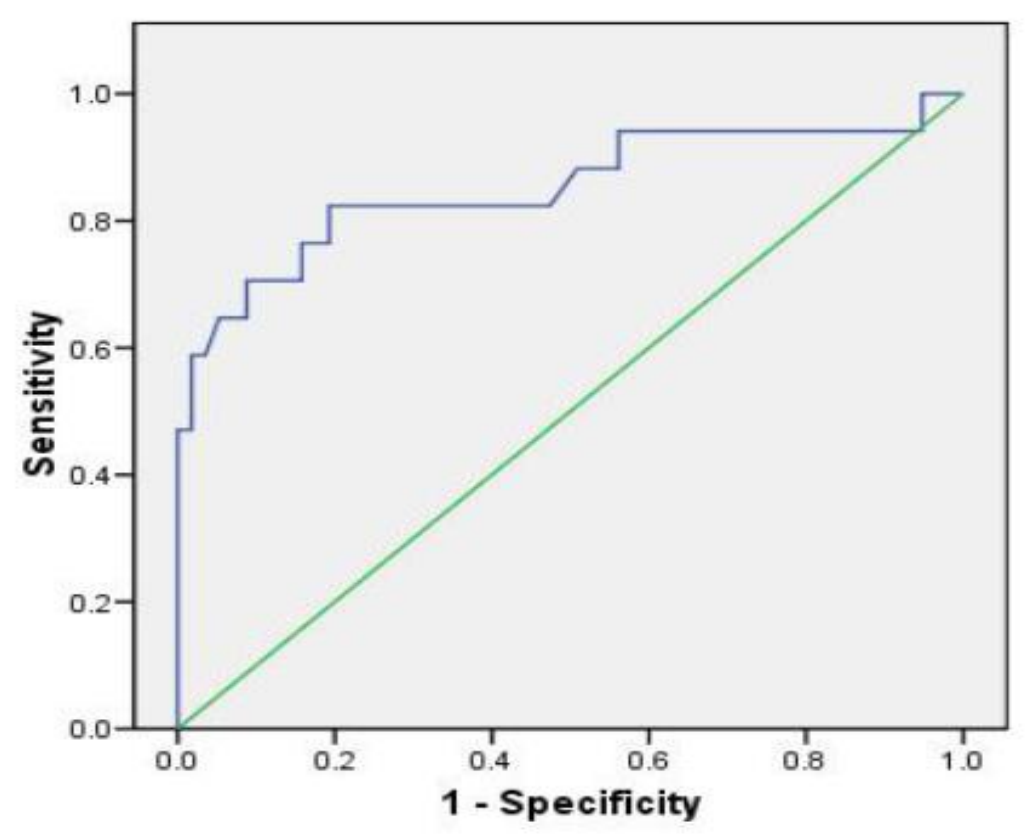

Diagonal segments are produced by ties.

Figure (3): ROC curve for corpus luteum volume in predicting termination of pregnancy in threatened abortion cases

\section{DISCUSSION}

In the study, the women of the three study groups didn't have statistically significant differences according to maternal age. These findings agreed with Dadkhah et al. (2010).

In the present study, when comparing the duration of bleeding between the threatened abortion (aborted) group and threatened abortion (continued) group was statistically significant. The results agreed with Dadkhah et al. (2010), the mean number of bleeding episodes and the amount of bleeding were more in the cases of poor pregnancy outcome (spontaneous preterm labor and placental abruption). Ocer et al. (2010) showed no statistically significant difference observed with respect to the duration of vaginal bleeding between the aborters and the patients with a favorable outcome. Nevertheless, when vaginal bleeding had been present for 3 days or more and there was high maternal serum CA125 activity, the abortion risk was found to be $100 \%$.

In this prospective study, transvaginal color doppler imaging was used to assess corpus luteum blood flow of both threatened abortion (aborted) group and threatened abortion (continued) group. Blood flow impedance in the corpus luteum was estimated by calculating the pulsitility index (PI) and peak systolic velocity (PSV). In addition, corpus luteum 
volume, measured using two-dimensional ultrasound, together with its presence or absence were correlated with the pregnancy outcome in the three study groups. When comparing the three study groups, the mean value of corpus luteum PI showed no statistically significant difference between the three groups.

On the other hand, when comparing the threatened abortion (aborted) group with the threatened abortion (continued) group and the control group, it was found that the mean corpus luteum PSV difference was statistically significant between threatened abortion (aborted) group and each of the threatened abortion (continued) group and the control group. While the difference was statistically nonsignificant between the threatened abortion (continued) group, and the control group.

The cut-off value of CL PSV at which there was a high probability of termination of pregnancy in threatened abortion cases, reached $17.8 \mathrm{~cm} / \mathrm{sec}$ with a sensitivity of $64.5 \%$ and specificity of $55.6 \%$.

These results disagreed with Frates et al. (2010) who showed no apparent correlation between the vascular aspects of the corpus luteum (resistive index, and peak systolic velocity) in early normal pregnancies and first-trimester pregnancy losses.

Salim et al. (2011) stated that both resistive and pulsatility indices were higher in patients with incomplete or threatened abortion in comparison with normal pregnancy. Alcazar and Perez (2012) assessed corpus luteum blood flow in patients diagnosed with abnormal early singleton pregnancy. No statistical differences in mean resistive index were found among threatened abortion pregnancy with respect to control group.

In this study, the corpus luteum was identified in all the cases of both threatened abortion cases who continued their pregnancy into the second trimester and the controls, while the corpus luteum was absent in $21.4 \%$ of threatened abortion who aborted afterwards, and was present in $78.6 \%$. The overall percentage of absent corpus luteum among the three study groups was $3 \%$, and the percentage of present corpus luteum was $97 \%$.

Mean corpus luteum volume showed a statistically significant difference when comparing the three groups.

The cut-off limit of CL volume of 4.1 cm3 was suggested by the study and achieved sensitivity of $85.7 \%$ and specificity of $83.3 \%$ in predicting termination of pregnancy in threatened abortion cases. These results agreed with Glock et al. (2010) who conducted a study to determine whether the size or change in size of the corpus luteum of early pregnancy were predictive of pregnancy outcome. A nonviable pregnancy occurred in $83 \%$ of women in whom a corpus luteum was undetectable by ultrasound, and in $31 \%$ of women in whom a corpus luteum was present.

On the contrary, the results disagreed with Frates et al. (2010) who showed no apparent correlation between the morphological aspects of the corpus luteum in early normal pregnancies and first-trimester pregnancy losses.

The present study evaluated the possible role of serum CA-125 measurement in the prognosis of first trimester abortion. Serum CA-125 levels 
were higher in threatened abortion (aborted and continued) group than in control group. There was a significant difference between each of the threatened abortion subgroups (aborted and continued) and the control group. Furthermore, in the threatened abortion group serum CA-125 levels were significantly higher in the aborted group than in the continued one. Therefore, there was a significant difference between these two groups as showed.

Ayaty et al. (2013) showed a significant difference between these two groups as well.

Fiegler et al. (2010) reported that a single serum CA-125 level determination is valuable in women with imminent abortion presenting with abdominal pain, vaginal bleeding or both. Kaminski et al. (2012) reported that women with threatening abortion revealed higher values of serum CA 125 antigen than those in control groups. The patients who had presented the highest values of the antigen later miscarried.

\section{The results of this study disagreed with some studies:}

Mahdi (2010) found that there was no statistically significant difference in CA125 levels of patients who aborted compared with those women that continued pregnancies despite its higher level. Also, Pareja et al. (2010) reported that there was no statistically significant difference in the CA 125 levels between the spontaneous aborted patients and the patients without abortion. Their study showed that serum CA 125 levels are not predictive of spontaneous abortion in the first trimester and failed to discriminate among threatened abortions, and normal pregnancies.

In this study, a cut-off limit of 31.9 $\mathrm{IU} / \mathrm{ml}$ of CA-125 level was suggested, with a sensitivity of $85.7 \%$ and specificity of $80 \%$. Several cut-off values were suggested in other studies in order to predict pregnancy outcome in early viable pregnancies complicated by vaginal bleeding or to discriminate between viable and non-viable gestations at the time of vaginal bleeding. Fiegler et al. (2010) used a cut off value of $66.5 \mathrm{IU} / \mathrm{ml}$ with a sensitivity of 55\%. Schmidt et al. (2010) used $65 \mathrm{IU} / \mathrm{ml}$ as a cut-off value and reported a sensitivity of $50 \%$ for this level. Romero-Gutiérrez et al. (2013) used a $125 \mathrm{IU} / \mathrm{ml}$ as a cut-off value and reported a $100 \%$ sensitivity and specificity.

\section{CONCLUSION}

There was a correlation between assessing both the CL vessels and volume on ultrasound examination and increased probability of early pregnancy loss. Serum CA-125 level determination was valuable in the women with symptoms of threatened abortion.

\section{REFERENCES}

1. Alcázar $J$ and Perez $M \quad$ (2012): Uteroplacental circulation in patients with first trimester threatened abortion. Fertility and Sterility, 73(1): 130-5.

2. Ayaty S, Roudsari F and Tavassoly F (2013): CA-125 in normal pregnancy and threatened abortion. Iranian Journal of Reproductive Medicine, 5(2): 57-60.

3. Cunningham FG, Leveno KJ and Bloom SL (2010): Abortion In: Williams Obstetrics, 22nd ed., Pbl. McGraw Hill, Pp. 215-34.

4. Dadkhah F, Kashanian $M$ and Eliasi $G$ (2010): A comparison between the pregnancy outcome in women both with and without 
threatened abortion. Early Human Development, 86: 193-196.

5. Devoto $L$, Kohen $P$, Muñoz $A$ and Strauss III J (2011): Human corpus luteum physiology and the luteal-phase dysfunction associated with ovarian stimulation. Reproductive BioMedicine Online, 18(2):19-24.

6. Fiegler P, Katz M, Kaminski K and Rudol G (2010): Clinical value of a single serum CA125 level in women with symptoms of imminent abortion during the first trimester of pregnancy. J Reprod Med., 48(12): 982-988.

7. Frates MC, Doubilet PM and Durfee SM (2010): Sonographic and Doppler characteristics of the corpus luteum: they can predict pregnancy outcome? J Ultrasound Med., 20(8):821-27.

8. Glock J, Blackman J, Badger $G$ and Brumsted J (2010): Prognostic significance of morphologic changes of the corpus luteum by transvaginal ultrasound in early pregnancy monitoring. Obstet Gynecol., 85: 37.

9. Kaminski $K$, Zwirska-Korczala $K$ and Fiegler $\mathbf{P}$ (2012): Level of CA-125 Ag in serum of first trimester normal and miscarried pregnancy. Wiad Lek., 55: 310-314.

10. Kim C, Barnard S, Neilson J, Hickey M, Vazquez $J$ and Dou L (2017): Medical Treatments for Incomplete Miscarriage. Cochrane Database of Systematic Reviews, 1: CD007223.

11. Mahdi B (2010): Estimation of CA-125 Level in First Trimester Threatened Abortion. The Internet Journal of Gynecology and Obstetrics, 12(2): 36-41.

12. Ocer F, Ilese T, Saridogan E, Aydinli K and Atasu T (2010): The prognostic significance of maternal serum CA 125 measurement in threatened abortion. Eur J Obstet Gynecol Reprod Biol., 16: 137-142.

13. Pareja OS, Urbanetz AA, Urbanetz LA, de Carvalho NS and Piazza MJ (2010): Echographic characteristics of the corpus luteum in early pregnancy: morphology and vascularization. Braz J Gynecol Obstet., 32(11): 549-55.

14. Predanic M, Chervenak FA and Reece EA (2010): Basic Principles of Ultrasound. Clinical Obstetrics-the Fetus and Mother, 6: 336-345.

15. Romero-Gutiérrez G, Abraham HuebeMartínez A, Amaral-Navarro I, Saúl RuizTreviño A and Saú A (2013): Doppler ultrasound assessment in women with threatened abortion. Assessment in Women with Threatened Abortion, 2(3): 24-28.

16. Salim A, Zalud I, Farmakides G, Schulman H, Kurjak A and Latin V (2011): Corpus luteum blood flow in normal and abnormal early pregnancy: evaluation with transvaginal color and pulsed Doppler sonography. J Ultrasound Med., 13: 971-78.

17. Schmidt T, Rein D and Foth D (2010): Prognostic value of repeated serum CA125 measurements in first trimester pregnancy. Eur J Obstet Gynecol Reprod Biol., 97: 168-173.

18. Silver RM, Branch DW and Goldenberg R. (2011): Nomenclature for pregnancy outcomes. Obstet Gynecol., 118(6): 1402-7. 


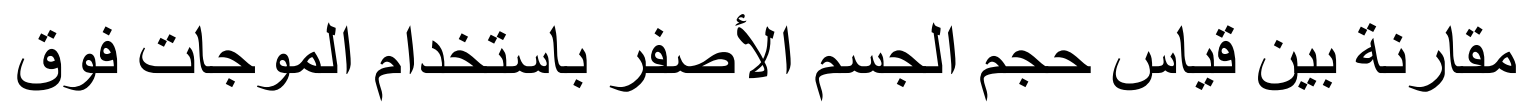

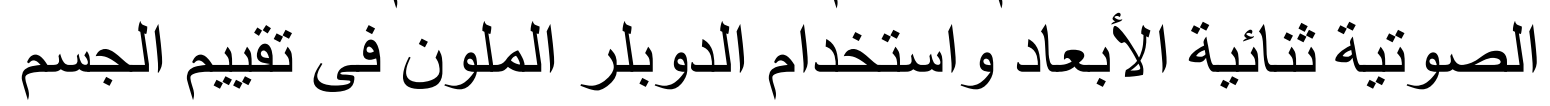
الأصفر وبين قياس مستوى المولد المضاد السرطانئ الادو 125 فى الدم للتنبوء بمصبر حالات الإجهاض المنذر في الثلاث

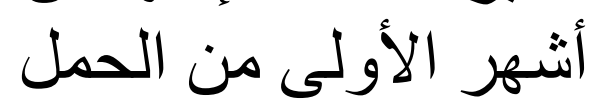

أيمن على عبد الرحمن نافع, يحيى عبد السلام وفا, أسامة السعيد على, وائل رفعت الصغ

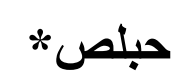

قسمي التوليد وأمراض النساء, والباتولوجيا الإكلينيكية*, كلية الطب، جامعة الأزهر

E-mail: dr.ayman.nafea@gmail.com

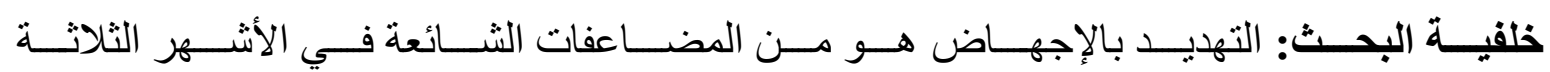

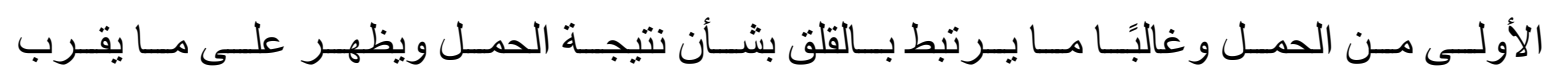

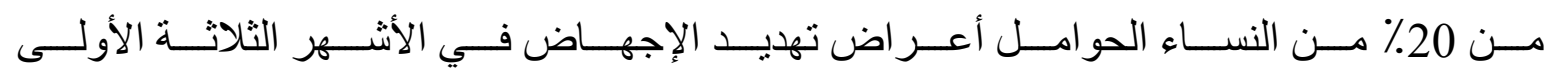

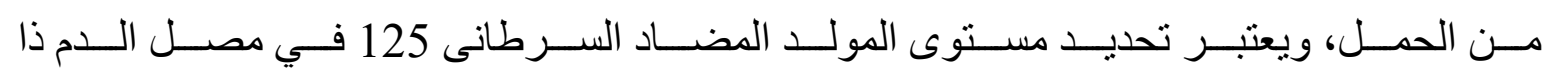

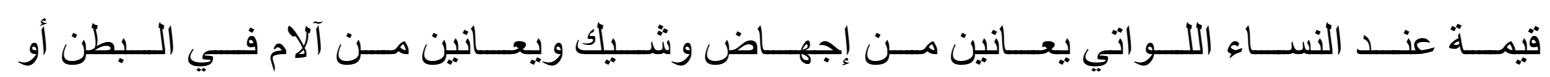
نزيف مهبلي أو كليهما بدلاً من القياسات التسلسلية.

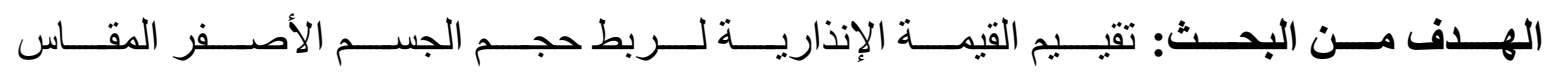

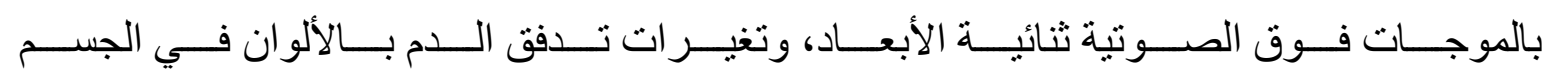

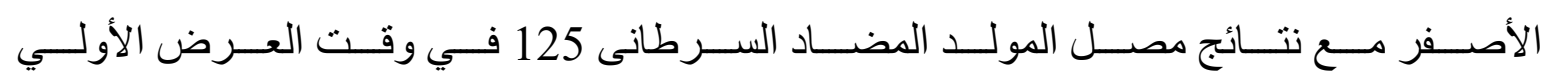
مع نتيجة الحمل لاى المرضى مع الإجهاض المهدد في الثلث الأول من الحمل.

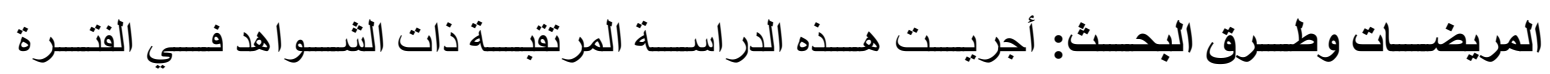

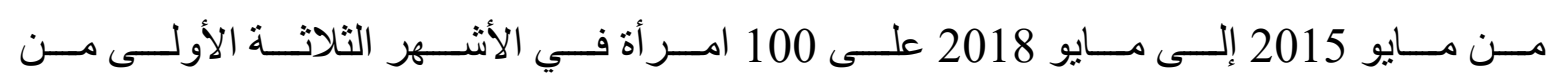

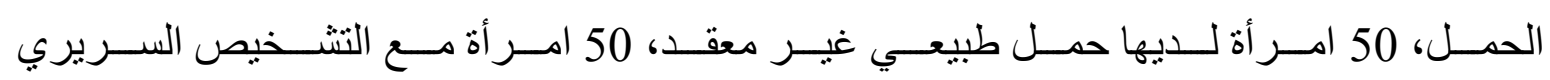

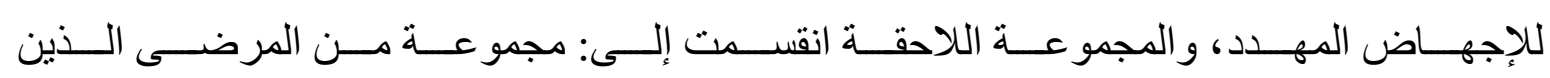

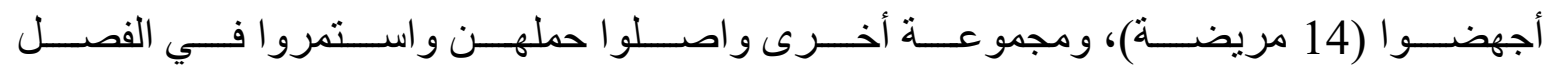
الثاني (36 مريضة). 


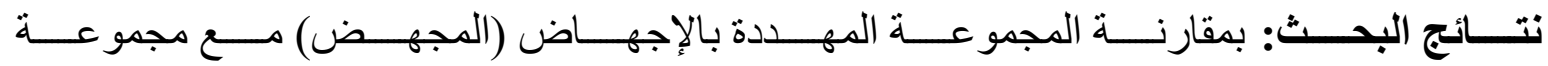

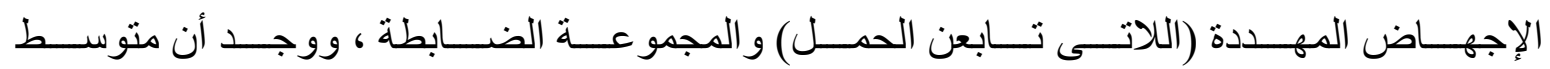

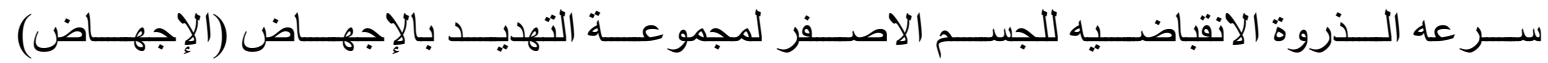

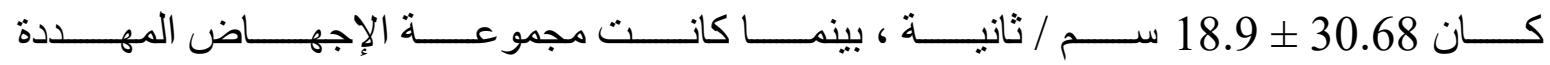

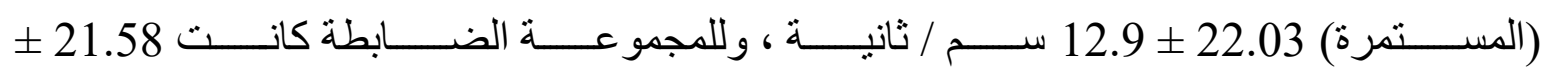

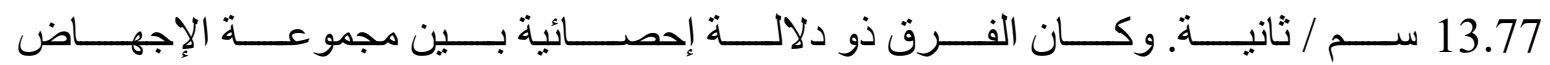

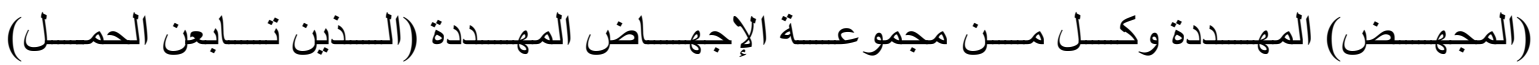

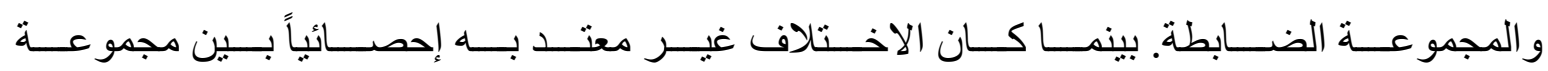

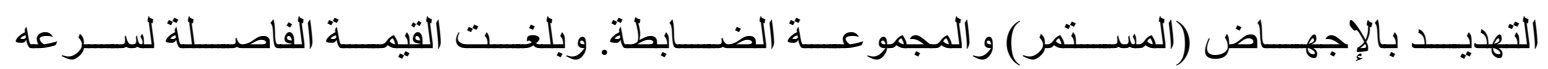

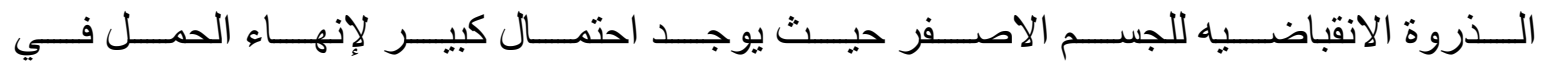

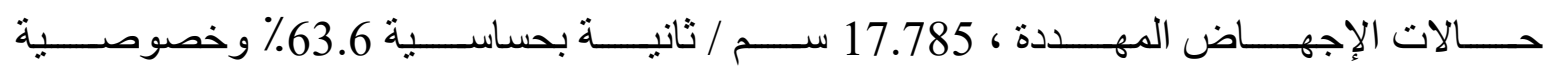
$\% 54.4$

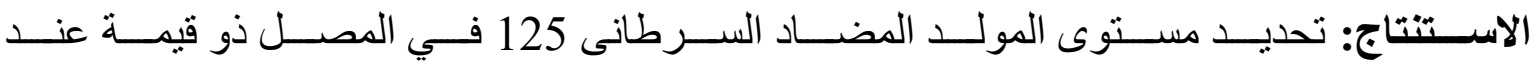

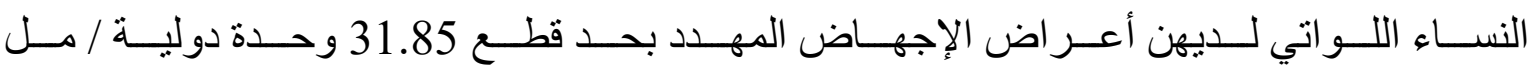

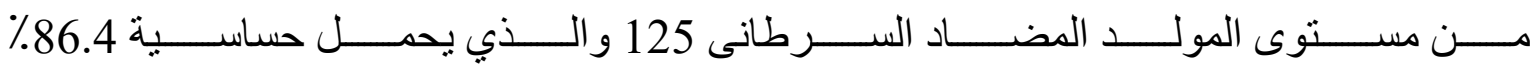

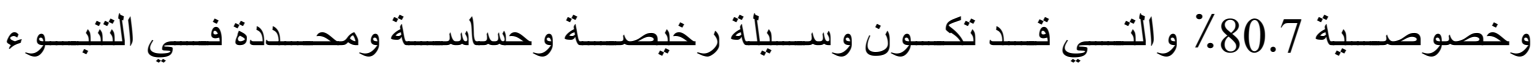

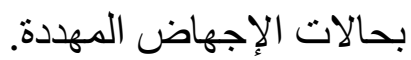

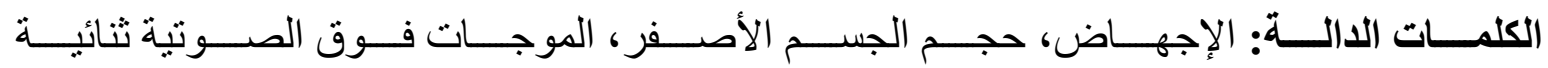

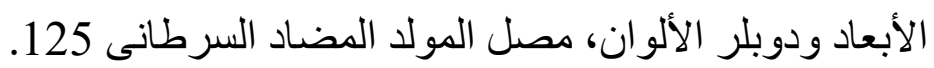

